\title{
A way of neodymium-iron-boron magnets regeneration in surface-mounted PMSM used in electric vehicles
}

\author{
A. ŁEBKOWSKI* \\ Department of Ship Automation, Gdynia Maritime University, 83 Morska Str., 81-225 Gdynia, Poland
}

\begin{abstract}
The paper describes an efficient method of magnetization of permanent magnets, mounted on synchronous and BLDC motor rotors, which employs an air coil. A developed mathematical model of an electromagnetic circuit is presented, which was simulated in an ANSYS-MAXWELL environment. The performed simulations and experimental tests allowed optimization of the physical process of magnetization of permanent magnets mounted on an electrical machine rotor. The adopted method allowed achieving more favourable conditions of magnetization - less financial expenditure allowed to achieve the same results.
\end{abstract}

Key words: permanent magnet, magnetization, synchronious motor, BLDC.

\section{Introduction}

Contemporary electric vehicle powertrains employ induction motors as well as permanent magnet synchronous motors (PMSM), which are built as surface (superficial) permanent magnet synchronous motors (SPM) or internal permanent magnet synchronous motors (IPM). A third type of motor used is permanent magnet brushless direct current motor (BLDC) with electronic commutation. In most of the former two types, the permanent magnets are neodymium sintered magnets (Nd-Fe-B or NIB). The intermetallic compound $\mathrm{Nd}_{2} \mathrm{Fe}_{14} \mathrm{~B}$, which forms the base of neodymium permanent magnets, was widely presented in 1983 by a Japanese researcher Masato Sagawa. With application of neodymium magnets on rotors of electrical machines, mostly synchronous motors, their operational parameters were enhanced. These units are characterized by simple construction, good matching of electro-mechanical characteristics to the needs of powered equipment, low operating costs with very good power efficiency, large dynamics due to low rotor inertia, and a possibility to achieve greater power than an equivalent induction motor of comparable size. Simultaneously, synchronous motors like all rotating machines are prone to damage, with permanent magnet machines being especially vulnerable. Permanent magnet motor damage can be broken down into: electric damage - associated with failures in field windings and field connections, mechanical damage of bearings, mechanical damage of magnets and the rotor itself and damage to motor control devices [1-5]. Apart from the listed problems, there is a possibility of electromagnetic and magneto-mechanic damage [6-8]. The permanent magnets applied on the rotor, when subjected to high temperature and electromagnetic field created by the field windings can

*e-mail: a.lebkowski@we.am.gdynia.pl

Manuscript submitted 2016-12-08, revised 2017-03-23, initially accepted for publication 2017-03-31, published in October 2017. become demagnetized. High temperature inside the motor can be a result of large loads or when the cooling system is not operating adequately. Another possible mode of failure exists, with the magnets become dislodged from their places by large centrifugal forces acting when the rotor spins at high speed. Freed magnets can then grind on the field laminations which causes them to rapidly heat up which together with high magnetic field in the air gap results in their demagnetization. In extreme cases this mechanism can lead to mechanical shattering or even pulverization into magnetic dust (Fig. 1). The surface mounted magnet motors (SPM) are especially prone to this mode of failure [9].

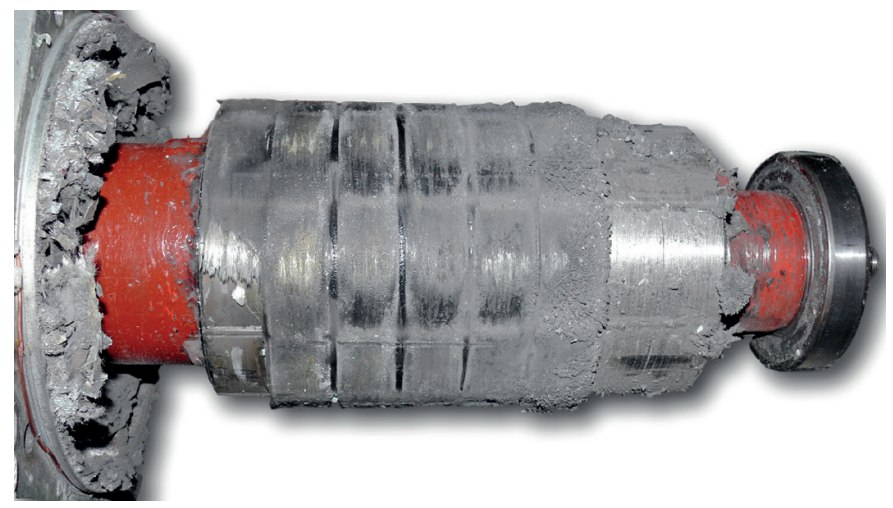

Fig. 1. The rotor of PMSM motor with damaged permanent magnets

Apart from the listed occurrences, during operation of a permanent magnet machine there is a possibility of the rotor becoming eccentric due to e.g.: manufacturing flaws, improper rotor mounting, bearing wear, wearing of the bearing sockets, mechanical damage to the shaft (bending) or a critical resonance condition during operation [10]. An important concern is also the application of proper motor control method [11, 12]. These 
faults negatively impact the motor's operation, which results in decreasing efficiency of the powertrain.

The paper presents the results of experimental and computational research for a single magnet placed in the field of an air coil, and for a magnet placed on a PMSM rotor of an electric vehicle. The experiments were performed by choosing the inductance parameters on a basis of simple analytic estimation for a circular coil presented in Section 2. However at a certain step of research, a decision was made to create the field model in the ANSYS-MAXWELL environment, which now takes into account the non-cylindrical shape of the tested object. The results of the simulations were used to determine the design of the coil used in the experimental studies.

\section{Estimation of the air coil inductance}

In order to restore the magnetic properties to magnets employed in synchronous motor rotors, various magnetizing coils are applied $[13,14]$. A simple and very efficient tool for restoring the magnetic properties of permanent magnets can be an air coil powered by a capacitor bank and switched with a thyristor (SCR).

For analytic estimation, in order to investigate the correctness of the model, the coil's self inductance was calculated using analytical equations [15-20]. It is assumed that the coil contains $\mathrm{N}$ circular turns, and the turns themselves are circular in cross-section (Fig. 2.). Therefore the coil's inductance will be a sum of self inductances of individual turns and mutual inductances between the turns, which can be calculated analytically.

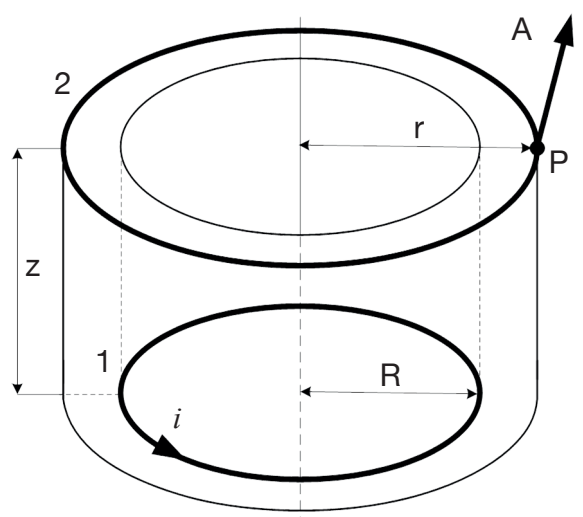

Fig. 2. Vector potential between turns of an air coil

For a symmetrical system of two turns (loops) 1, 2 of the coil, the vector potential in the point $\mathbf{P}$, deriving from the current $\boldsymbol{i}$ is specified by the relationship

$$
\mathbf{A}=\frac{\mu_{0} \cdot i}{2 \pi} \sqrt{\frac{R}{r}}\left[\left(\frac{2}{k}-k\right) K-\frac{2}{K} E\right]
$$

where $k=\frac{4 R r}{z^{2}+(R+r)^{2}}$

$\mathrm{K}$ and $\mathrm{E}$ - complete elliptic integrals of $1^{\text {st }}$ and $2^{\text {nd }}$ kind, respectively.

The mutual inductance between a pair of turns is

$$
M=\frac{\Phi_{12}}{i} \mu_{0} \sqrt{r \cdot R}\left[\left(\frac{2}{k}-k\right) K-\frac{2}{K} E\right]
$$

Using the formula for a vector potential, an external flux penetrating a turn can be calculated, which defines an external inductance of a thin wire.

$$
L_{z}=\mu_{0} R\left[\left(\frac{2}{k}-k\right) K-\frac{2}{K} E\right]
$$

Since an external inductance of a single turn is small, an internal inductance should be taken into account. The total inductance $\mathrm{L}_{\mathrm{c}}$ of a single turn is therefore a sum of the external inductance $\left(L_{z}\right)$ and internal inductance $\left(L_{w}\right)$. Finally, the inductance L of a circular air coil containing $\mathrm{N}$ turns can be calculated using the following relationship

$$
L=\sum_{j=1}^{N} L_{c_{j}}+\sum_{j=1}^{N} \sum_{n=1}^{N} M_{n j}
$$

where

$L_{c_{j}}-$ self inductance of a j-turn

$M_{n j}$ - mutual inductance between a n-turn and j-turn

\section{Simulation tests}

In order to perform simulation tests, a model has been created in the ANSYS-MAXWELL environment. An external circuit powering the coil is presented in Fig. 3.

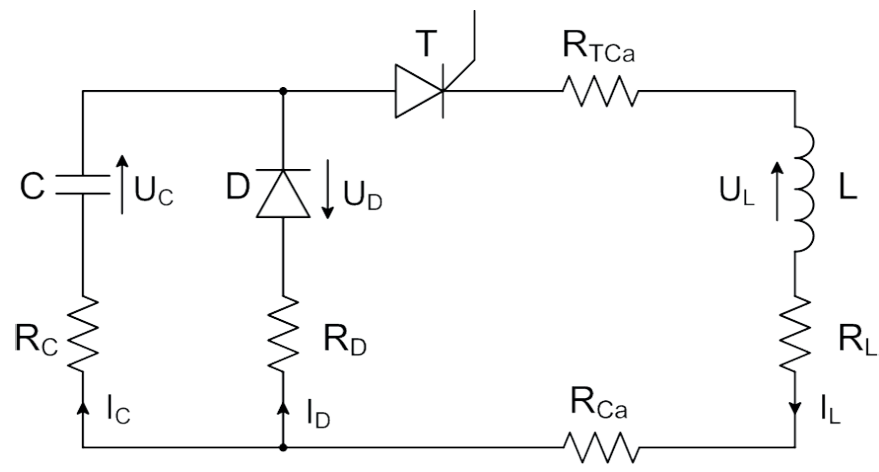

Fig. 3. Schematic of the modelled electrical circuit, where: C-capacitor bank, $\mathrm{R}_{\mathrm{C}}$-capacitor bank resistance, $\mathrm{D}$-diode, $\mathrm{R}_{\mathrm{D}}$-diode resistance, $\mathrm{T}$-thyristor ( $\mathrm{SCR}$ ), $\mathrm{L}$-air coil inductance, $\mathrm{R}_{\mathrm{L}}$-coil resistance, $\mathrm{R}_{\mathrm{TCa}}$-thyristor resistance including resistance of connecting wires, $\mathrm{R}_{\mathrm{Ca}}-$ connection wires resistance 
Parameters of components used in modeled and experimental tests are presented in the table 1.

Table 1

Parameters of components used in modeled and experimental tests

\begin{tabular}{|l|c|c|}
\hline Parameter & Value & Unit \\
\hline Capacitor bank capacity $\mathrm{C}$ & 58 & $\mathrm{mF}$ \\
\hline Capacitor bank voltage $\mathrm{U}_{\mathrm{C}}$ & 400 & $\mathrm{~V}$ \\
\hline Capacitor bank resistance $\mathrm{R}_{\mathrm{C}}$ & 0,3 & $\mathrm{~m} \Omega$ \\
\hline Diode resistance $\mathrm{R}_{\mathrm{D}}$ & 0,6 & $\mathrm{~m} \Omega$ \\
\hline Coil inductance $\mathrm{L}$ & 2,26 & $\mu \mathrm{H}$ \\
\hline Coil resistance $\mathrm{R}_{\mathrm{L}}$ & 2,86 & $\mathrm{~m} \Omega$ \\
\hline $\begin{array}{l}\text { Thyristor resistance including } \\
\text { resistance of connecting wires } \mathrm{R}_{\mathrm{TCa}}\end{array}$ & 0,44 & $\mathrm{~m} \Omega$ \\
\hline Connection wires resistance $\mathrm{R}_{\mathrm{Ca}}$ & 0,1 & $\mathrm{~m} \Omega$ \\
\hline
\end{tabular}

The coil has been simulated as a ring having the following dimensions (external diameter $D_{O}=100 \mathrm{~mm}$, internal diameter $D_{I}=60 \mathrm{~mm}$, coil height $D_{g}=15 \mathrm{~mm}$ ) (Fig. 4.).

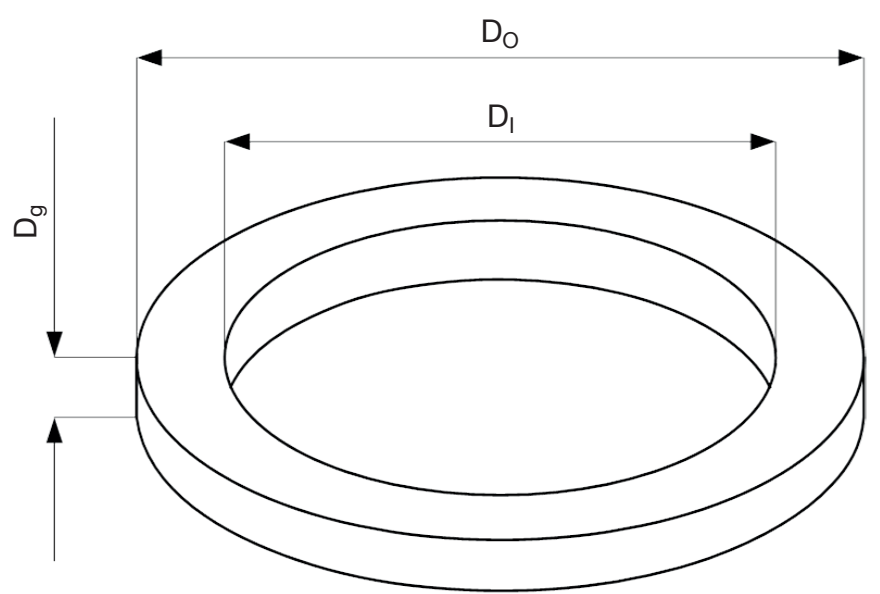

Fig. 4. Physical dimensions of the coil

The neodymium permanent magnet dimensions, and location in relation to the coil is presented in Fig. 5.

For the designed coil with an external circuit, the ANSYS-MAXWELL program does not automatically calculate the resistance of that coil. Because of that, and minding that the dynamic change of current has an impact on coil's resistance as a result of skin effect, the coil resistance was determined experimentally, and input into the model.

The experimental determination of dynamic resistance was based on a registration of transient current during discharge of the capacitor through the coil without a core (neodymium

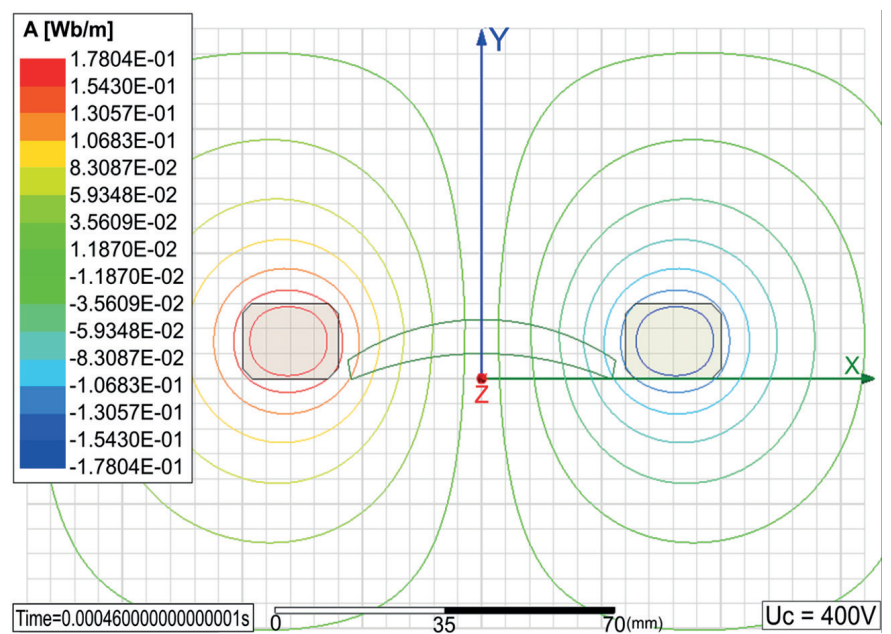

Fig. 5. Magnetic flux (maximum value at the time $\mathrm{t}=0,46 \mathrm{~ms}$ )

magnet) present, with the assumed known capacitance and initial voltage.

At the same time, due to the negligible impact of parasitic inductance on the results, it was not taken into account in the model. Fig. 6 presents a vector distribution of magnetic induction at supply from the maximum voltage on a capacitor of $400 \mathrm{~V}$.

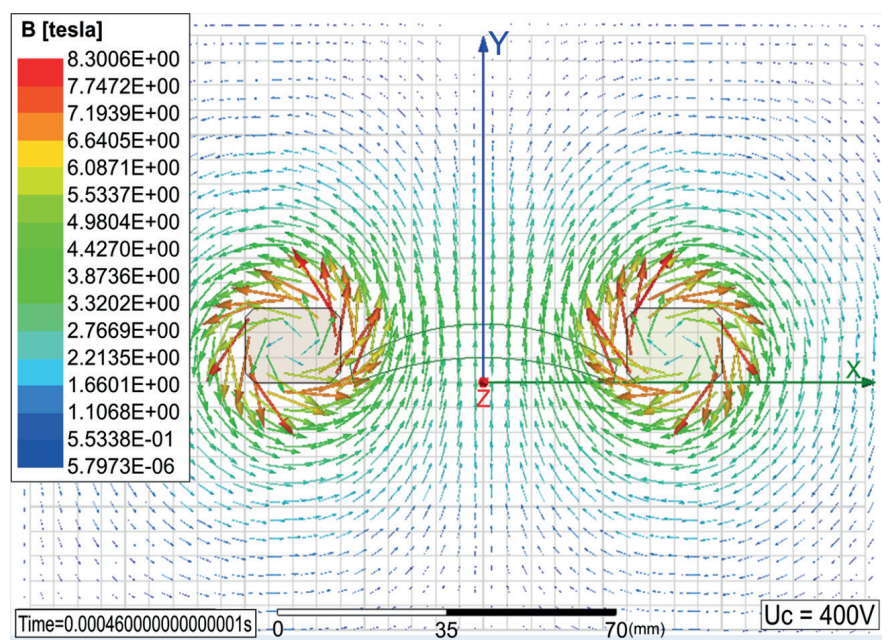

Fig. 6. Vector distribution of the magnetic induction (maximum value at the time $\mathrm{t}=0,46 \mathrm{~ms}$ )

For a coil with an external circuit, the ANSYS-MAXWELL program does not automatically calculate the coil resistance. For this reason, taking into account the dynamic current changes having an effect on the dynamic changes of the coil resistance as a result of an evident skin effect, the coil resistance has been determined experimentally and input into the model. Simultaneously, due to negligible effect on the results, the coil model does not include the parasitic inductances present in the circuit. 


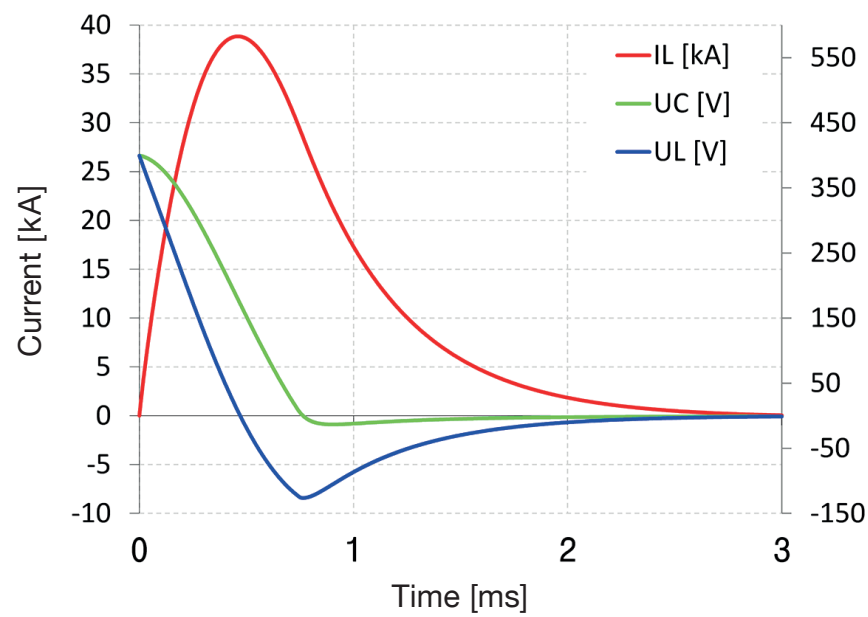

Fig. 7. The plot of coil current $\left(\mathrm{I}_{\mathrm{L}}\right)$ and capacitor bank voltage $\left(\mathrm{U}_{\mathrm{C}}\right)$ and coil voltage $\left(\mathrm{U}_{\mathrm{L}}\right)$ as a function of time, for the initial value of $\mathrm{Uc}=400 \mathrm{~V}$

The plot of magnitudes of current $\mathrm{I}_{\mathrm{L}}$, voltages $\mathrm{U}_{\mathrm{C}}$ and $\mathrm{U}_{\mathrm{L}}$ is presented in Fig. 7 .

Although the shape of the coil encompassing the neodymium magnets was closer to a rectangle, for analytic estimation in order to check the correctness of the model, the inductance of a circular coil calculated with analytical formulae
$(\mathrm{L}=2,26 \mu \mathrm{H})$ was compared to the inductance from the model (for rectangular coil $\mathrm{L}=2,2542 \mu \mathrm{H}$ ). The compared values were similar, and the difference was less than $1 \%$.

Fig. 8 presents a countour plot of magnetic induction for capacitor bank voltage of, respectively, $400 \mathrm{~V}, 250 \mathrm{~V}$ and $200 \mathrm{~V}$. It can be incurred from the plot that the minimum capacitor bank
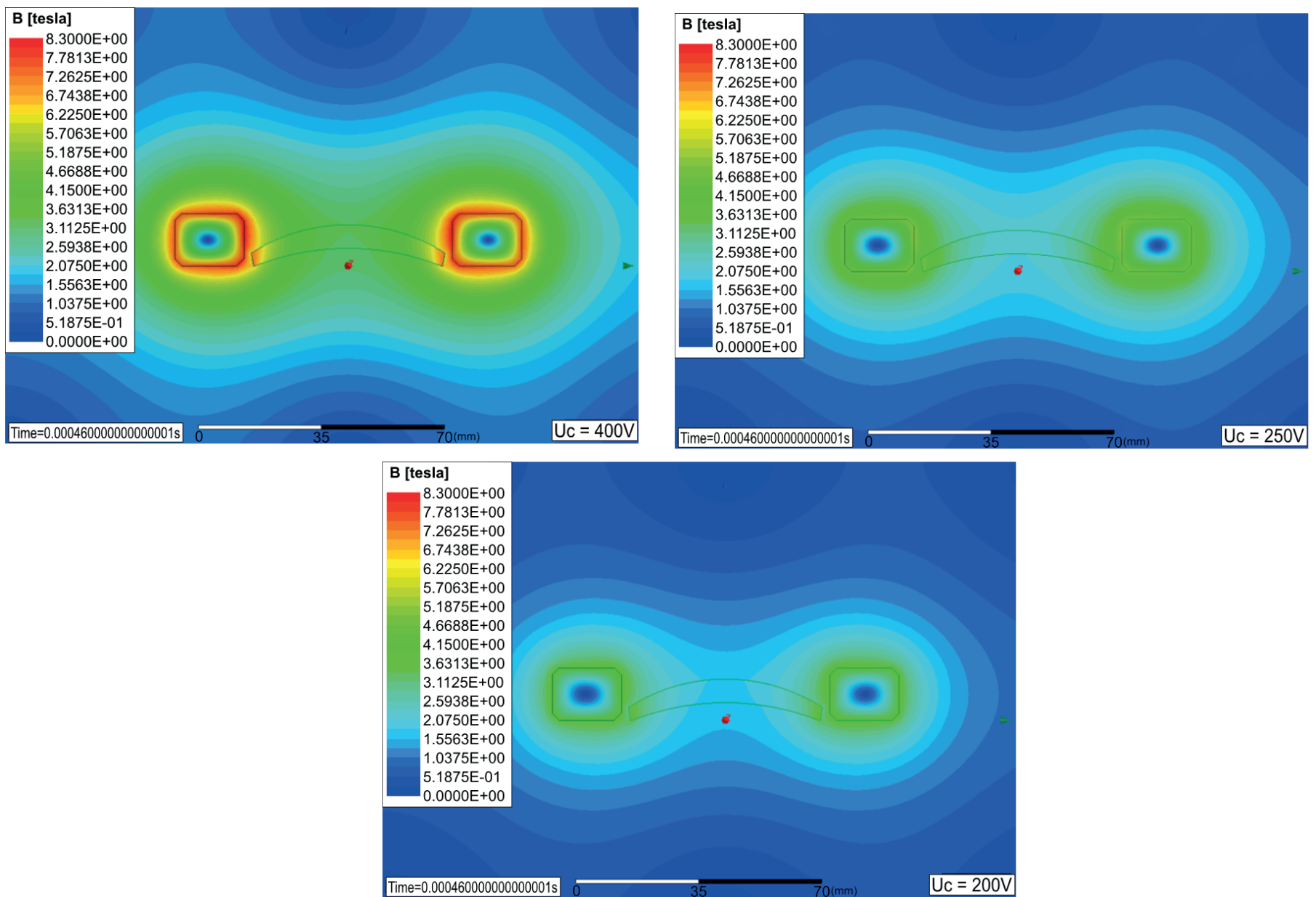

Fig. 8. Contour plot of magnetic induction for coil and neodymium magnet (maximum value at the time $\mathrm{t}=0,46 \mathrm{~ms}$ ) 
voltage allowing proper magnetization of permanent magnets of same dimension as in the figure, and constructed from the material N38UH is $250 \mathrm{~V}$.

Figure 9 shows the contour distribution of magnetic induction for a model consisting of an air coil and a neodymium magnet mounted on the rotor surface of the motor for the voltage generated by the capacitor banks at $400 \mathrm{~V}$. The figure shows that mounting the magnet on a rotor has an insignificant impact on the distribution of magnetic induction which performs the magnetization process.

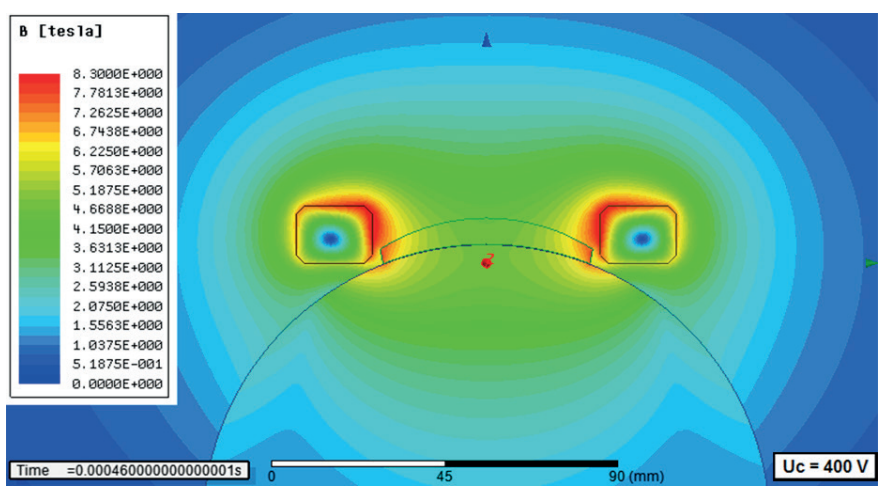

Fig. 9. Contour plot of magnetic induction for coil with neodymium magnet (maximum value at the time $\mathrm{t}=0,46 \mathrm{~ms}$ )

Fig. 10 shows the plots of current $\left(\mathrm{I}_{\mathrm{L}}\right)$ and voltage $\left(\mathrm{U}_{\mathrm{L}}\right)$ on the coil as a function of time, for the initial voltage of the capacitor bank in the range $50 \div 400 \mathrm{~V}$ with a step of $25 \mathrm{~V}$.

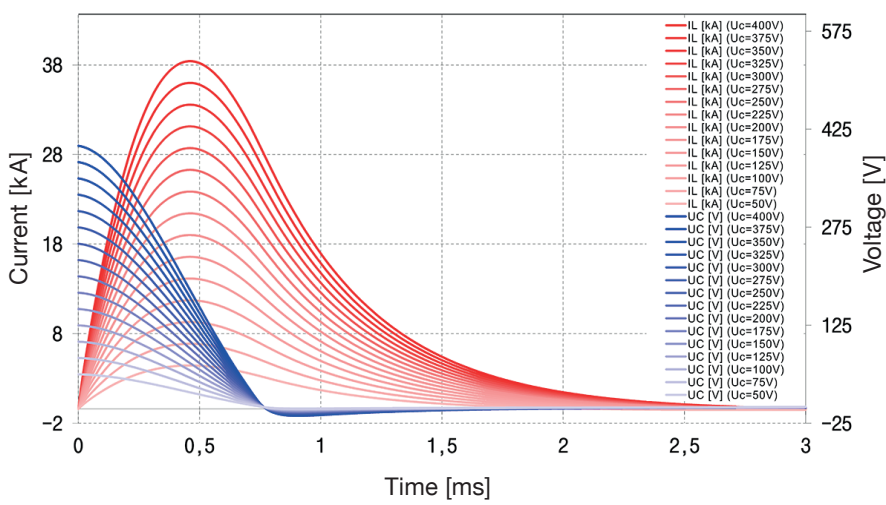

Fig. 10. The plot of coil currents $\left(\mathrm{I}_{\mathrm{L}}\right)$ and coil voltages $\left(\mathrm{U}_{\mathrm{L}}\right)$ as a function of time, for the initial value of capacitor bank voltage from the range $50 \div 400 \mathrm{~V}$ with a step of $25 \mathrm{~V}$

\section{Experimental tests}

The magnetization method of neodymium permanent magnets has been verified by an experiment, using electrotechnical components. The components used during testing (capacitor bank, air coil, thyristor (SCR), diode and transformer with diode bridge) are presented in Fig. 11.

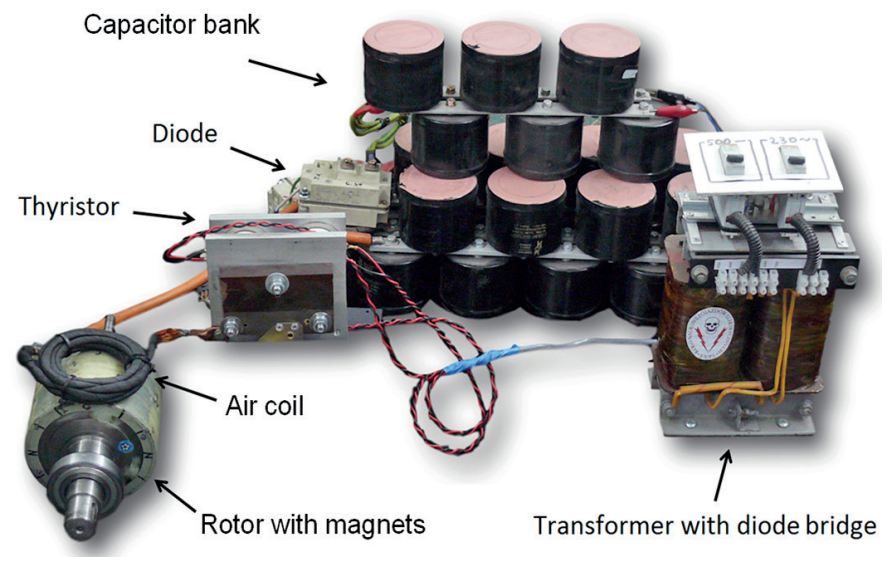

Fig. 11. View of actual electrotechnical components used for the experiment

During the tests, the permanent magnets being magnetized were of type N38UH, and were previously demagnetized by application of high temperature in excess of magnetic material Curie temperature.

Neodymium sintered magnets (Nd-Fe-B) are belonging to a group of modern permanent magnetic materials, with the compound $\mathrm{Nd}_{2} \mathrm{Fe}_{14} \mathrm{~B}$ (Neodymium Iron Boron) forming their base [21]. They are the strongest magnets presently offered in the market. Fig. 12 presents a four quadrant plot describing the magnetizing force relative to resultant magnetization of a permanent magnet material. Subsequent quadrants describe successive magnetization, up to the point of saturation (1-2), magnetic remanence (3), demagnetization (3-4), magnetization

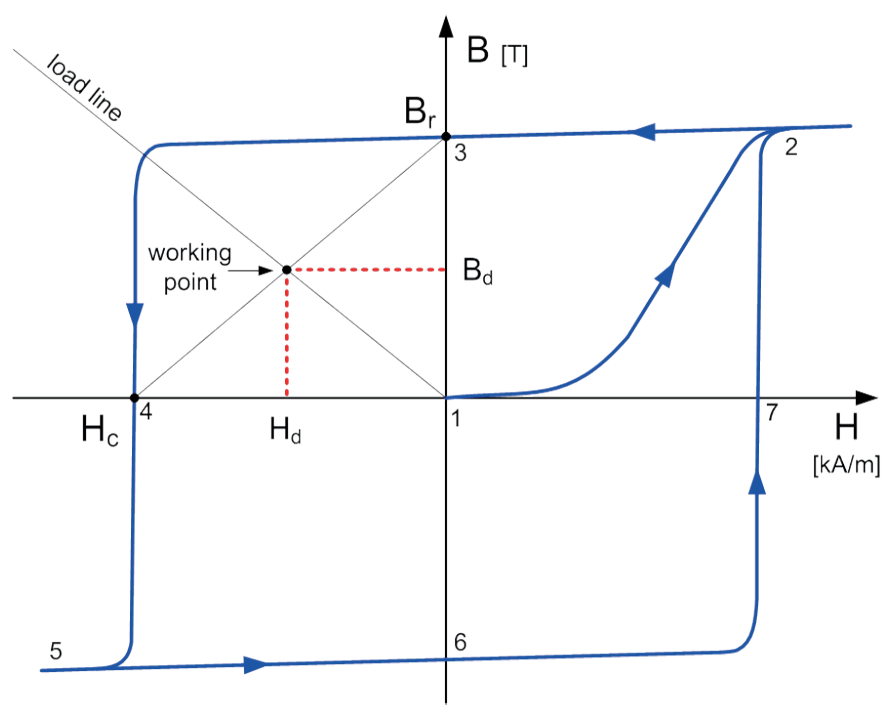

Fig. 12. Demagnetization curves for magnets, where: $H_{c}($ Coercive Force, Coercivity)-value of external magnetic field which has to be exerted on the magnet in order to bring its magnetic field intensity to zero.; $\mathrm{B}_{\mathrm{r}}$ (Residual Induction, Remanence) -value of magnetic induction with external magnetic field turned off.; $B_{d}$ (Remanent induction), is any magnetic induction that remains in a magnetic material after removal of an applied saturating magnetic field; $\mathrm{H}_{\mathrm{d}}$ is that value of $\mathrm{H}$ corresponding to the remanent induction $\mathrm{B}_{\mathrm{d}}$ 


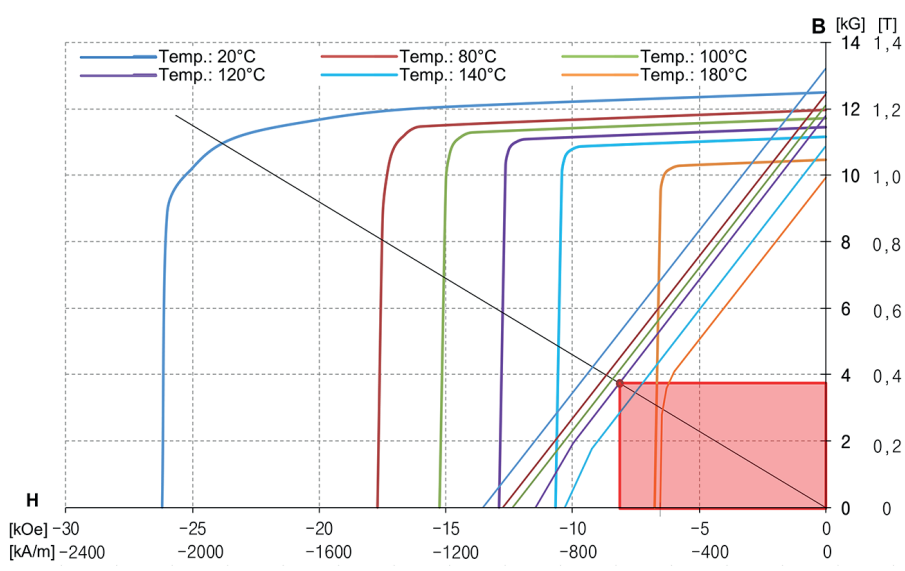

Fig. 13. Demagnetization curves for $\mathrm{N} 38 \mathrm{UH}$ magnets at temp. $120^{\circ} \mathrm{C}[21]$

in the opposite direction (4-5-6), and finally remagnetized in the original direction (6-7). In order to describe the properties of magnetic materials (remanence, coercivity), the second quadrant of the hysteresis loop is used. The properties of the N38UH neodymium sintered magnet used in the experiment are presented in Fig. 13. Every magnet has a property related to its own demagnetization field. The coefficient associated with the measure of possibility of the material to create magnetic field (the degree of magnetization, or permeance coefficient or permeability or recoil permeability $\mathrm{m}_{\mathrm{r}}$ ) depends on the size of the magnet and operating conditions. The recoil permeability is described by a following relationship

$$
\mu_{r}=\frac{\Delta B}{\Delta H}
$$

The coefficient $\mathrm{m}_{\mathrm{r}}$ describes the facility of the magnetic flux flowing from the north pole of the magnet, to the south pole. From this coefficient, the magnet working point can be derived. The higher the value of $\mathrm{ofm}_{\mathrm{r}}$, the harder it is to change the polarity of the magnet. The area between the points $\mathrm{H}_{d}-\mathrm{W}_{\mathrm{P}}-\mathrm{B}_{\mathrm{d}}$ defines the magnitude of energy density of the magnet with a particular physical size, and made with a given magnetic material [22-29].

Assuming the part of the hysteresis loop lying in the second quadrant is linear, the magnet magnitude of energy density can be also approximated by following equation [24].

$$
(B H)_{M A X}=\frac{1}{4 \cdot \mu_{0} \cdot \mu_{r}} B_{r}^{2}
$$

where $\mu_{0}$ - vacuum permeability.

The advantage of neodymium magnets is a large maximum energy density $\mathrm{BH}_{\max }$ which, depending on the physical size is between 286 and $310 \mathrm{~kJ} / \mathrm{m}^{3}$. For comparison the $\mathrm{BH}_{\max }$ for ferrite magnets is up to $35 \mathrm{~kJ} / \mathrm{m}^{3}$, for AlNiCo magnets up to $80 \mathrm{~kJ} / \mathrm{m}^{3}$, for samarium-cobalt ( $\left.\mathrm{Sm}-\mathrm{Co}\right)$ magnets up to $240 \mathrm{~kJ} / \mathrm{m}^{3}$, neodymium bonded magnets (Nd-Fe-B) up to $100 \mathrm{~kJ} / \mathrm{m}^{3}$, neodymium sintered magnets (Nd-Fe-B) up to $412 \mathrm{~kJ} / \mathrm{m}^{3}$ ). Another advantage is a large value of remanence $\mathrm{Br}$ which, depending on the physical size of the N38UH magnet, is on the order of $1.25 \mathrm{~T}$, and large magnitude of coercive force $\mathrm{Hc}$ in excess of $2000 \mathrm{kA} / \mathrm{m}$ and large coercivity $\mathrm{Hd}$ in excess of $800 \mathrm{kA} / \mathrm{m}$. These parameters allow the operation of such magnets in the presence of large demagnetizing fields.

A slight disadvantage of neodymium sintered magnets is the maximum working temperature which, for N38UH magnet (Fig. 13) is $180^{\circ} \mathrm{C}$ with a temperature coefficient of remanence $\mathrm{TK}(\mathrm{Br})$ of $-0,10 \div-0,12 \% /{ }^{\circ} \mathrm{C}$, and temperature coefficient of coercive force $\mathrm{TK}(\mathrm{Hc})$ of $-0,6 \% /{ }^{\circ} \mathrm{C}$ and Curie Point(Tc) of $310 \div 340^{\circ} \mathrm{C}$ [21-28]. The measurements of magnetic induction of permanent magnets were made with a linear Hall effect sensor type HE144, calibrated with a standard magnet, with a known magnetic induction [30].

A damaged (demagnetized) magnet (Fig. 14) is placed inside the air coil, in the correct position, depending on the desired polarization ( $\mathrm{N}$ or $\mathrm{S}$ on the top). After charging the capacitor bank, and triggering the thyristor, the intensity of the magnetic field created by the coil allowed to establish the desired polarity and magnitude of magnetic induction (Fig. 15).

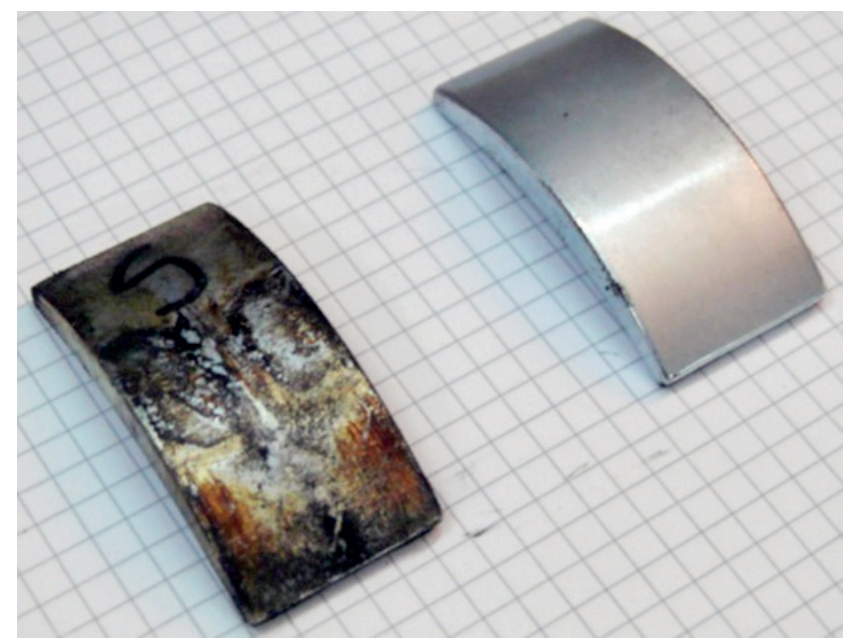

Fig. 14. N38UH magnets - a damaged magnet on the left, a new magnet on the right

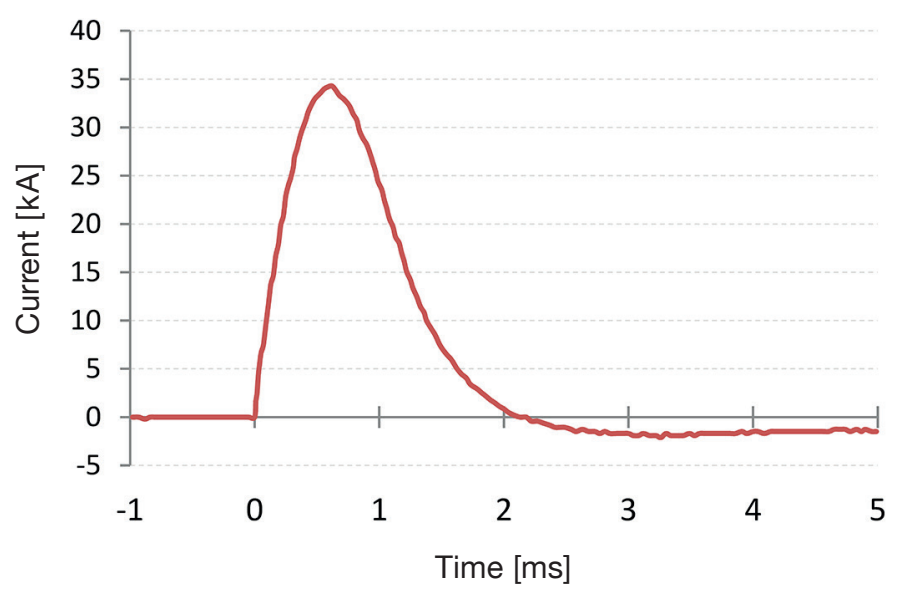

Fig. 15. The plot of coil current during actual experimental test (with achieved maximum current of $34.2 \mathrm{kA}$ at $\mathrm{Uc}=400 \mathrm{~V}$ 


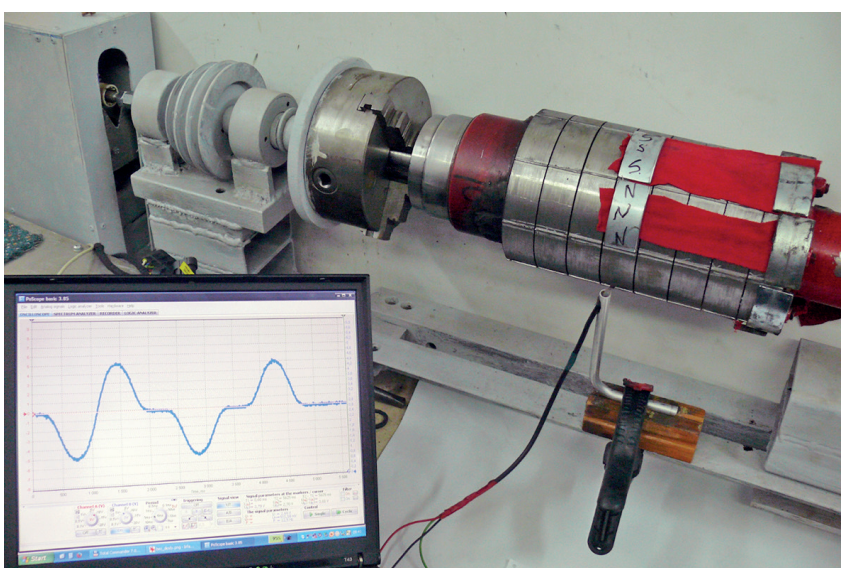

Fig. 16. PMSM rotor with damaged permanent magnets

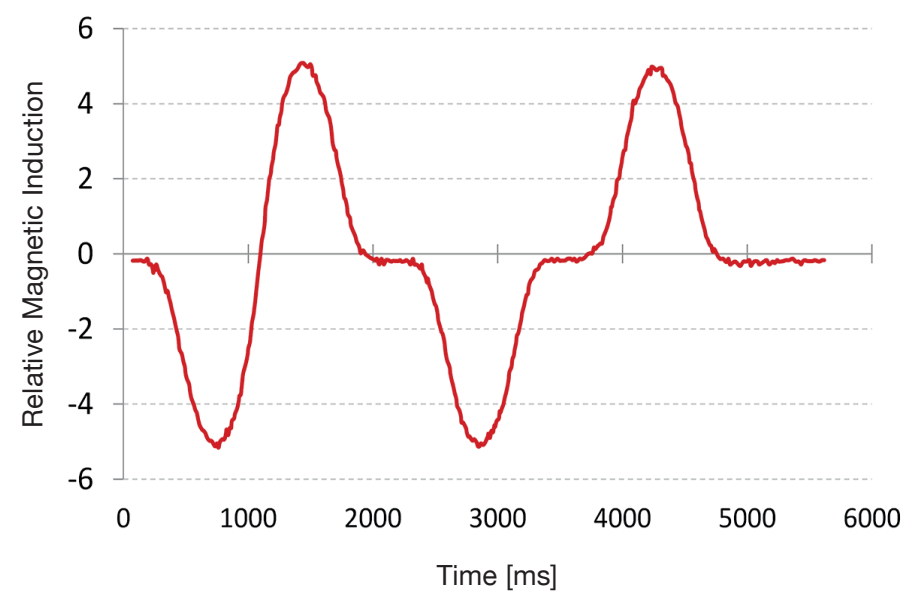

Fig. 18. Plot of relative average value of magnetic induction of regenerated magnets mounted on a PMSM rotor

During the tests, it is crucial to maintain safety, as large magnitude of magnetic flux can propel the magnet out of the coil, or tear apart the coil when it is not properly secured.

Fig. 17 presents the plot of relative average value of magnetic induction measured in the middle part of the permanent magnet mounted on a rotor held in a rotating jig (Fig. 16).

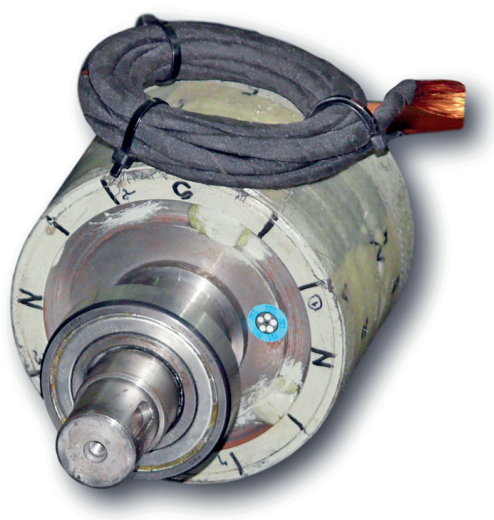

Fig. 20. Placement of the air coil on the neodymium magnet mounted on a PMSM rotor

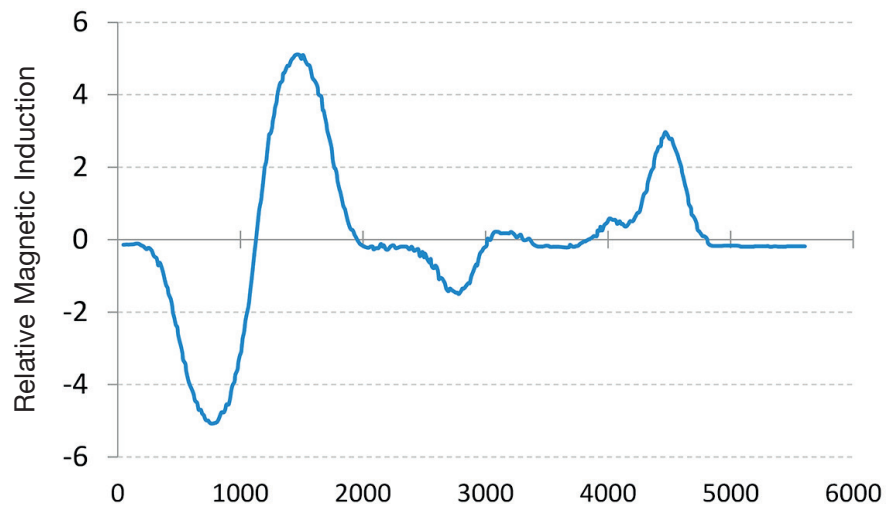

Fig. 17. Plot of relative average value of magnetic induction of damaged magnets mounted on PMSM rotor

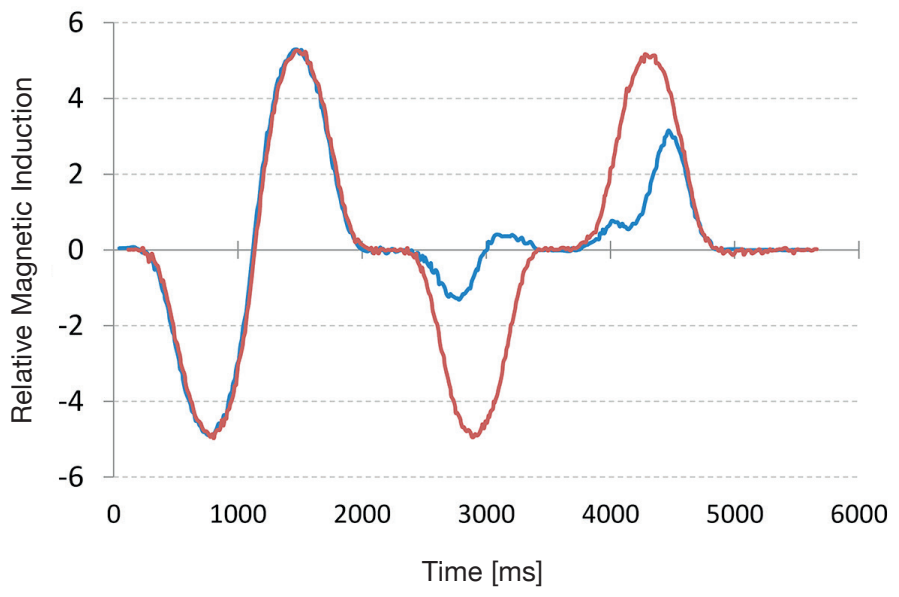

Fig. 19. Superimposed plots of relative average value of magnetic induction of same magnets before and after regeneration

Basing on the plot presented in Fig. 17, it can be ascertained that two permanent magnets do not possess the required value of magnetic induction. Subsequently, the magnets were taken off the rotor, and remagnetized with the air coil. The magnets were remounted on the rotor in order to measure the magnetic induction. The results are presented in Fig. 18.

The proposed method for regeneration of permanent magnets used to construct rotors of synchronous motors has confirmed its practical usefulness (Fig. 19).

Due to the fact that the flux created by the air coil can be modified by changing the voltage on the capacitor bank, an attempt of magnetization of neodymium sintered magnets was made while the magnets were mounted on the rotor, without their removal (Fig. 20). The magnetization was performed on the rotor of a motor, which was diagnosed with a few of the magnets having a reduced magnetic induction.

\section{Conclusions}

The proposed method of regeneration of permanent magnet used in permanent magnet synchronous motors has proven its practical usability. 
Thanks to simple construction of the air coil, the required magnetic induction level can be restored in the neodymium sintered magnets employed in PMSM rotors. The results of performed computer simulations using the ANSYS-MAXWELL software, and verification experiments have proven that the obtained magnitude of magnetic induction is fully sufficient to magnetize any neodymium sintered magnet, which geometric dimensions are close to that of an air coil, and which thickness is not exceeding $30 \mathrm{~mm}$. The conducted tests have proven the repeatability of achieved effects. The measurements of magnetic induction on the surface of magnets did not differ by more than $6 \%$.

A clear advantage of presented method is that it does not require the regenerated magnets to be taken off the rotor. It allows to reduce the cost of rotor repairs, due to the fact that it requires less time and that it does not require any special resins, glues, or special thermally set tapes or fibers.

\section{REFERENCES}

[1] G. Vinson, M. Combacau, T. Prado, and P. Ribot, "Permanent magnets synchronous machines fault detection and identification", IEEE IECON 2012, Montreal, 3925-3930 (2012).

[2] M. Akar, M. Hekim, and U. Orhan, "Mechanical fault detection in permanent magnet synchronous motors using equal width discretization- based probability distribution and a neural network model", Turkish Journal of Electrical Engineering and Computer Sciences 23 (3), (2015).

[3] T. Goktas, M. Zafarani, K.W. Lee, B. Akin, and T. Sculley, "A comprehensive analysis of magnet defect fault monitoring through leakage flux", IEEE Transactions on Magnetics 99, (2016).

[4] Y. Ge, Y. Mollet, B. Song, and J. Gyselinck, "Detection and isolation of asymmetrical short-circuit faults in permanent-magnet synchronous machines", IEEE International Energy Conference, 1-6 (2016).

[5] P. Witczak, M. Witczak, J. Korbicz, and Ch. Aubrun, "A robust predictive actuator fault-tolerant control scheme for Takagi-Sugeno fuzzy systems", Bull. Pol. Ac.: Tech. 63 (4), (2015).

[6] J.D. Bisschop, A. Abdallh, P. Sergeant, and L. Dupré, "Identification of demagnetization faults in axial flux permanent magnet synchronous machines using an inverse problem coupled with an analytical model", IEEE Transactions on Magnetics 50 (11), (2014).

[7] M. Akar and M. Eker, "Demagnetization of fault diagnosis in permanent magnet synchronous motors", Przegląd Elektrotechniczny 89 (2a), (2013).

[8] H. Liu, H. Lin, Z. Q. Zhu, M. Huang, and P. Jin, "Permanent magnet remagnetizing physics of a variable flux memory motor," IEEE Trans. Magn. 46 (6), 1679-1682, (2010).

[9] K. Sakai, K. Yuki, Y. Hashiba, N. Takahashi, and K. Yasui, "Principle of the variable-magnetic-force memory motor," Proc. ICEMS, Tokyo, 1-6 (2009).

[10] M. Akar, S. Taskin, S. Seker, and I. Cankaya, "Detection of static eccentricity for permanent magnet synchronous motors using the coherence analysis", Turkish Journal of Electrical Engineering and Computer Sciences 6, (2010).

[11] S. Karyś, "Advanced control and design methods of the auxiliary resonant commutated pole inverter", Bull. Pol. Ac.: Tech. 63 (2), 489-494 (2015).
[12] J. Bernat, S. Stepień, A. Stranz, G. Szymański, and J.K. Sykulski, "Infinite time horizon optimal current control of a stepper motor exploiting a finite element model", Bull. Pol. Ac.: Tech. 62 (4), 835-841 (2014).

[13] W.N.Fu, Y.Chen, "A post-assembly magnetization method for a line-start permanent-magnet motor", IEEE Transactions on Applied Superconductivity 26 (4), (2016).

[14] D.D. Reigosa, D. Fernandez, Z.Q. Zhu, and F. Briz, "PMSM magnetization state estimation based on stator-reflected PM resistance using high-frequency signal injection", IEEE Transactions On Industry Applications 51 (5), (2015).

[15] P. Jankowski, "Analytic-numerical approach in modeling electrodynamic phenomena of inductive dynamic drive", Journal of the Chinese Institute of Engineers, 39 (1), 79-86, (2016).

[16] P. Jankowski, J. Mindykowski, and M. Woloszyn, "Effect of power frequency on the stress state of disc actuator", International Journal of Applied Electromagnetics and Mechanics 45, (1-4), 639-647, (2014).

[17] P. Jankowski, M. Woloszyn, "Suitability study of hybrid model of electrodynamic actuator", International Journal of Applied Electromagnetics and Mechanics 45, (1-4), 649-657, (2014).

[18] D. Spałek, "Two theorems about Lorentz method for asymmetrical anisotropic regions", Bull. Pol. Ac.: Tech. 61 (2), 399-404 (2013).

[19] A. Demenko, "Representation of windings in the 3-D finite element description of electromagnetic converters", IEE Proceedings- Science Measurement And Technology 149 (5), 186-189 (2002).

[20] A. Demenko, "Description of electrical machine windings in the finite element space", COMPEL - The International Journal for Computation and Mathematics in Electrical and Electronic Engineering 27 (4), 711-719, (2008).

[21] J.F. Herbst, J.J. Croat, and F.E. Pinkerton, "Relationships between crystal structure and magnetic properties in Nd2Fe14B", Physical Review B 29 (7), (1984)

[22] www.kjmagnetics.com (11.2016)

[23] www.magnets-magnets.eu (11.2016)

[24] S. Tumański, Handbook of Magnetic Measurements, CRC Press, 2016.

[25] J. Liu, "Some design considerations using permanent magnets", Magnetics Business \& Technology 3 (2016).

[26] L. Liu, H. Sepehri-Amin, T. Ohkubo, M. Yano, A. Kato, N. Sakuma, T. Shoji, and K. Hono, "Coercivity enhancement of hot-deformed Nd-Fe-B magnets by the eutectic grain boundary diffusion process using Nd62Dy20A118 alloy", Scripta Materialia 129, 44-47, (2017)

[27] Y. Hirayama, T. Miyake, and K. Hono, "Rare-earth lean hard magnet compound NdFe12N", Journal of the Minerals, Metals \& Materials Society (TMS) 67 (6), 1344-1349, (2015).

[28] Y. Hirayama, Y.K. Takahashi, S. Hirosawa, and K. Hono, "NdFe12Nx hard-magnetic compound with high magnetization and anisotropy field", Scripta Materialia 95, 70-72 (2015).

[29] J. Wang, H. Sepehri-Amin, Y.K. Takahashi, S. Okamoto, S. Kasai, J.Y. Kim, T. Schrefl, and K. Hono, "Magnetization reversal of FePt based exchange coupled composite media", Acta Materialia 111, 47-55 (2016).

[30] Advanced Sensor Technology, Analog Hall Sensor HE144 www.hoeben.com/products-he144.html (2016). 